\title{
ANÁlise DOS APONTAMENTOS DO TCE-MT NAS CONTAS PÚBLICAS DOS MUNICÍPIOS DA REGIÃO MÉDIO NORTE DO MATO GROSSO
}

\author{
Roberto Alves Cabral ${ }^{1}$ \\ Magno Alves Ribeiro ${ }^{2}$
}

\begin{abstract}
RESUMO
O presente artigo tem como objetivo analisar as irregularidades nas contas públicas anuais dos municípios da região Médio Norte do Estado de Mato Grosso, apontadas nos relatórios de auditoria do Tribunal de Contas do Estado (TCE-MT), por estarem em desacordo com a Lei de Responsabilidade Fiscal (LRF). O estudo abordou uma pesquisa qualitativa descritiva, documental eletrônica (telematizada), na qual foram revisados 50 relatórios de auditoria das contas públicas de 10 municípios no período de 2006 à 2010, a partir dos quais, foi possível identificar 172 irregularidades com a LRF, que foram classificadas em gravíssimas, graves e não classificadas, e 34 infrações com a LRF-Cidadão. As irregularidades identificadas em descumprimento dos princípios da LRF estiveram presentes em 26 artigos, dos quais, pelos critérios aplicados, foram classificados 6 artigos para análise das principais irregularidades da LC 101/2000 apontadas nas contas públicas dessas gestões municipais pesquisadas. Também foram comparados os municípios apontados em maior número de infrações e os municípios que pouco apresentou violações na lei, classificando-os em ranking pela natureza da gravidade dessas infrações. Ao final, concluiu-se que as irregularidades apresentadas por essas gestões municipais não condizem ao pleno atendimento dos dispositivos da transparência e equilíbrio das receitas e despesas trazidas na LC 101/2000, colocando em dúvidas, perante a lei, a gestão fiscal e responsável dessas gestões.
\end{abstract}

Palavras-chave: Lei de Responsabilidade Fiscal (LRF). Irregularidades na LC 101/2000. LRF-Cidadão. Relatórios de auditoria. Parecer prévio.

\section{INTRODUÇÃO}

Os absurdos casos de corrupção no Brasil ainda motivam muita desconfiança por parte de sua população nas políticas públicas de gerenciamento dos recursos financeiros, fazendo com que a imagem do país passasse a ser vista pelas mídias internacionais como farras extravagantes do dinheiro público. Criada em 2000, a Lei Complementar de $\mathrm{n}^{\circ}$ 101, mais conhecida como a Lei de Responsabilidade Fiscal (LRF) visou mudar esse cenário do mal uso do dinheiro público, trazendo em seus mecanismos a fiscalização, o controle e o planejamento das ações nas contas públicas prestadas pelas gestões governamentais.

Os assuntos relacionados ao uso do dinheiro público sem dúvida abrem os olhos de qualquer indivíduo envolvido na sociedade, isso porque, através dos tributos arrecadados dos cidadãos é dada a maior fonte geradora de recursos que o governo disponibiliza, entretanto

1 Acadêmico do curso de Ciências Contábeis da UNEMAT - Campus de Tangará da Serra, e-mail: roberto.castelomdc@hotmaiLCom

${ }^{2}$ Mestre em Administração Y Finanzas pela Universidade Extremadura (2003). Professor do curso de Ciências Contábeis da UNEMAT - Campus de Tangará da Serra, e-mail: magnoalves@ unemat.br 
Análise dos apontamentos do TCE-MT nas contas públicas dos municípios da região Médio Norte do Gato Grosso

Roberto Alves Cabral

Magno Alves Ribeiro

nem sempre a contrapartida destes recolhimentos é repassada de forma adequada que atendem a necessidade da coletividade em serviços públicos de qualidade. A LRF trouxe em seus objetivos a transparência nas contas públicas, limitação em gastos com os recursos públicos, e ainda, um controle ao endividamento que ocorria nas mudanças de gestões.

A lei tem a finalidade de responder à sociedade a sérios problemas em relação a decisões adotadas por gestores à utilização de recursos públicos. $\mathrm{O}$ descontrole com o dinheiro público decorria em desvio e entre outras irregularidades, no qual chegou a classificar a corrupção como endêmica no Brasil. Nesse sentido buscou-se um pensamento no equilíbrio das contas públicas, gastar com base naquilo que se arrecada, norteou a idéia da criação da lei (PEREIRA; SILVA, 2009). A LRF é um dos mecanismos aguardado por muito tempo no controle dos gastos exorbitantes no setor público, sendo que a sociedade tanto se indignou com a corrupção presente na administração pública brasileira.

A importância desse estudo é contribuir de forma que a sociedade possa acompanhar e fiscalizar as atividades de ordem pública, estimulando o interesse em abordar questões relacionadas às aplicações dos recursos financeiros. A cultura brasileira de fiscalização por parte dos cidadãos ainda é muito tímida, em sua maioria, as transparências governamentais são divulgadas em meio eletrônico através de sites em internet, vistos que estudos apontam que nem toda população possuem acessos a internet. Espera que as informações trazidas nesse artigo possam chegar ao Poder Legislativo Municipal, para que cada prestação de contas dos prefeitos possa ser revisada levando em consideração os princípios da LRF.

Desde a criação da LRF, o Estado de Mato Grosso vem demonstrando ao longo dos anos preocupação quanto os cumprimentos legais dos municípios em relação a essa lei, em 2003, o Tribunal de Contas do Estado (TCE-MT), alertou 96 municípios para o cumprimento da LRF, a fim de prevenir os gestores públicos do cumprimento de suas metas orçamentárias (GIRADELO, 2003). No ano de 2009, o TCE-MT emitiu 164 termos de alerta aos municípios, esses avisos teve função preventiva, justamente para alertar o prefeito de que ele deve retomar os rumos de sua gestão (OLIVEIRA, 2009).

Os estudos de Silva e Ribeiro Filho (2008), abordaram as ressalvas nas contas aprovadas pelo TCE-PE nas prefeituras da região metropolitana de Pernambuco, no período de 2000 a 2005, buscando evidenciar os fatores determinantes de tais pendências. No final desta pesquisa, os resultados levantados demonstraram que as ressalvas apresentadas nos 
Análise dos apontamentos do TCE-MT nas contas públicas dos municípios da região Médio Norte do Gato Grosso

Roberto Alves Cabral

Magno Alves Ribeiro

pareceres do TCE-PE repetiram-se nos municípios, principalmente no ano de 2001, sendo apontadas falhas nos Controles Internos.

Adotando por base o trabalho de Silva e Ribeiro Filho (2008), esta pesquisa tem como objetivo geral analisar as irregularidades nas contas públicas anuais dos municípios da região Médio Norte do Estado de Mato Grosso, apontadas nos relatórios de auditoria do TCE-MT, por estarem em desacordo a LRF; e que se desdobra nos seguintes objetivos específicos: identificar os itens que contém irregularidades nas contas públicas quanto ao não atendimento da LRF; analisar os relatórios do TCE-MT sobre as irregularidades da LRF e; comparar os relatórios das contas públicas dos municípios.

Sendo assim, levantou o seguinte problema a ser investigado: Quais foram as principais irregularidades em relação à LRF apontadas pelo TCE-MT nas prestações de contas públicas dos municípios do Médio Norte de MT nos anos de 2006 à 2010 ?

\section{REFERENCIAL TEÓRICO}

\subsection{Os municípios}

No cenário político-administrativo brasileiro apresenta um modelo federativo altamente descentralizado, na inclusão do Município como ente federado, com autonomia política, administrativa e financeira, com governo próprio e funções exclusivas, determinadas explicitamente pela Constituição Federal (TAVARES, 2009). Os municípios são pessoas de direito público interno, compõe a União, mas por se encontrarem no espaço territorial dos Estados, integram de forma singular o sistema federativo brasileiro (KOHAMA, 2006).

O município foi consagrado na Constituição Federal como ente público indispensável ao nosso sistema federativo, integrando-o na organização político-administrativo e garantindo-lhe plena autonomia (MORAES, 2007), alcançando um lugar de destaque no pacto federativo constituído na Carta Magna, nunca antes obtida na trajetória constitucional pátria (FERNANDES, 2008). A partir do processo de descentralização, foram atribuídos aos municípios e estados ampla autonomia para legislar, arrecadar tributos, gerir, despender e fiscalizar seus recursos, ainda que essa autonomia é precária, já que, na maioria dos casos, os entes federativos estão na dependência financeira quase total da União (MORAIS, 2008).

O município é a única instância efetiva da vida real, são neles onde os problemas e as soluções surgem, na qual as melhores, mais eficazes e duradouras soluções são as que 
Análise dos apontamentos do TCE-MT nas contas públicas dos municípios da região Médio Norte do Gato Grosso

Roberto Alves Cabral

Magno Alves Ribeiro

aparecem no âmbito do próprio município (MORAIS, 2008). A dependência seja da União, ou do estado em que estivessem situados, os municípios não poderiam caracterizar em autonomia, pois dependente não teria domínio em arrecadar e aplicar suas próprias rendas ou escolher os membros de seus poderes (FERNANDES, 2008).

\subsection{Lei Complementar $\mathbf{n}^{0} \mathbf{1 0 1}$ de 2000}

Criada em 04 de maio do ano de 2000, a Lei Complementar de ${ }^{\circ}$ 101/2000 conhecida também como a Lei de Responsabilidade Fiscal (LRF), foi elaborada com objetivo de transparecer a responsabilidade dos gestores no emprego apropriado do dinheiro e dos recursos públicos. A Lei Complementar 101/2000 determina regulamentos de finanças públicas de responsabilidade na gestão fiscal, que pressupõe a ação planejada e transparente, em que se previnem riscos e corrigem desvios capazes de comprometer o equilíbrio das contas públicas (BRASIL, 2000).

Diante da utilização de recursos econômicos escassos, a LRF é um instrumento legal que demonstra a aplicação do modelo econômico da burocracia, estabelecendo responsabilidades, mas, também, objetivos e metas ao gestor público (DALMONECH; TEIXEIRA; SANT'ANNA, 2011). A chegada dessa lei foi fundamental para novos conceitos de processos e mecanismos nas gestões públicas até então realizadas no Brasil, a LRF estabeleceu, de fato, um marco histórico no país, porque transformou a cultura institucional até então vigente na administração pública brasileira (OLIVEIRA, 2008).

A LRF é uma lei de amplo alcance, regulamentando aspectos do controle das arrecadações e dos gastos governamentais, sendo que a sua execução representa uma inflexão na maneira como os governos devem lidar com a gestão e aplicação de recursos públicos, estabelecendo alterações substanciais nas normas de planejamento e controle das contas públicas, visando, principalmente, à disciplina fiscal (SODRÉ, 2002). Notadamente no que se menciona o conhecimento do contribuinte no processo de acompanhamento da aplicação dos recursos públicos e de avaliação dos seus resultados, cria condições para a implantação de uma nova cultura gerencial na gestão dos recursos públicos e estimula o exercício completo da cidadania (CAMARGO; SEHNEM, 2010).

Além de instituir normas orientadoras das finanças públicas, a LRF preencheu uma lacuna da Lei 4.320/64, ao estabelecer severas punições para aqueles governantes que não 
Análise dos apontamentos do TCE-MT nas contas públicas dos municípios da região Médio Norte do Gato Grosso

Roberto Alves Cabral

Magno Alves Ribeiro

souberem administrar os recursos públicos durante o seu mandato, deixando dívidas para seus sucessores e assumindo compromissos que sabem, de antemão, não poder honrar (MARCUZZO; FREITAS, 2004). Em relação as penalidades, o artigo 73 da LRF discorre que as infrações aos dispositivos da lei serão punidas de acordo com o Código Penal de 1940, a Lei $n^{0} 1.079$ de 1950, o Decreto-Lei $n^{0} 201$ de 1967, a Lei $n^{\circ} 8.429$ de 1992 e demais normas da legislação pertinente (BRASIL, 2000).

Cumpre ressaltar que a Lei 10.028 de 2000 alterou as leis de penalidades tratadas no art. 73 da LRF, acrescentando nas redações dessas leis ênfases nos crimes contra as finanças públicas. Existem dois tipos de penalidades para não cumprimento da LRF, que são as punições fiscais, que correspondem ao impedimento do ente para o recebimento de transferências voluntárias, a contratação de operações de crédito e a obtenção de garantias para a sua contratação, e por outro lado tem as sanções penais, que envolvem o pagamento de multa com recursos próprios (podendo chegar a 30\% dos vencimentos anuais), a inabilitação para o exercício da função pública por um período de até 5 anos, a perda do cargo público e a cassação de mandato, e, finalmente a prisão (NASCIMENTO, 2001).

Ainda, Nascimento (2001) destaca alguns exemplos de transgressões à LRF e suas punições penais, sendo:

\section{Transgressão}

Contratação irregular de op. de crédito

Alienação de bens sem autorização

Descumprir o orçamento aprovado

Não reduzir despesas com pessoal

Liquidação de aros fora dos prazos legais

\section{Punição}

- reclusão de 1 a 2 anos.

- perda de cargo, reclusão.

- cassação de mandato.

- multa de $30 \%$ dos vencimentos.

- perda de cargo, inabilitação.

A edição da LRF foi mais um passo dado na direção do equilíbrio das contas públicas, contudo, só foi possível graças ao fim do ciclo inflacionário que maquiava os orçamentos públicos e inutilizava o planejamento governamental (SOUZA, 2010) e com a aprovação pode ser entendida como um balizador no que se refere às finanças públicas no Brasil. A partir dessa lei foi estabelecido orientações normativas para que o aprimoramento da gestão fiscal dos recursos públicos fosse executado (CAMARGO; SEHNEM, 2010). 


\subsubsection{Os desafios dos municípios na Lei de Responsabilidade Fiscal}

A sociedade conviveu há anos a falta de responsabilidade na gestão fiscal, careceu da criação de mecanismos que coibissem o mau uso de recursos públicos, de maneira que ela fosse adequada ao acompanhamento das ações dos gestores públicos, e sobre tudo deveria estar à vista dos olhos dos cidadãos (SOUZA et al, 2010). Partiu da necessidade de um ajuste fiscal para que levasse o legislador pátrio a aprovar a Lei de Responsabilidade Fiscal (LRF), cujos resultados fossem transformar os déficits orçamentários anuais em orçamentos equilibrados (BIRCK; SHIKIDA; SCHALLENBERGER, 2004).

Embora a LRF tenha trazido novos conceitos, novas diretrizes e resultados positivos, demonstrou uma série de fatores que ela pode provocar algumas distorções no equilíbrio federativo, prejudicando a execução de políticas no intuito de diminuir os desequilíbrios regionais (SANTOLIN; JAYME JR.; REIS, 2009). As prefeituras foram as mais atingidas em razão de sua responsabilidade direta em executar programas e prestar uma gama de serviços públicos (CAMARGO; SEHNEM, 2010), os gestores municipais têm sofrido uma pressão para gerenciar com eficiência e sejam eficazes nos resultados, já que os recursos, que são escassos, são disputados para atenderem a novas necessidades (SANTOS; ALVES, 2011).

Os municípios na estrutura organizacional têm papel de destaque, pois são vistos como os que mais bem podem atender às demandas da população por estarem mais próximos de seus problemas e, supostamente, de suas soluções (GERIGK; CLEMENTE; TAFFAREL, 2010). Os gestores municipais encontram dificuldades quantos os recursos financeiros que dispõe, ao cumprimento das obrigações impostas pela LRF gerou despesas aos municípios para as quais não havia fonte de custeio (GARRIDO, 2008), impactou para as administrações públicas não só pelo surgimento de novos instrumentos e métodos de controle gerencial voltados para o controle e minimização do gasto público, mas pelo caráter impositivo de obrigatoriedade legal como forma de disciplina fiscal (SILVA; BONACIM, 2010).

Mesmo depois de alguns anos que a LRF entrou em vigor, prefeitos e vereadores municipais continuaram sendo flagrados pelos Tribunais de Contas por irregularidades e fraudes com recursos públicos. Segundo auditorias promovidas pelos Tribunais de Contas, as violações mais comuns à regra fiscal são: restos a pagar sem disponibilidade financeira, aumento do nível de endividamento e da dívida ativa, déficit orçamentário, resultado financeiro, econômico e patrimonial negativos, gastos com serviços terceirizados além do 
Análise dos apontamentos do TCE-MT nas contas públicas dos municípios da região Médio Norte do Gato Grosso

Roberto Alves Cabral

Magno Alves Ribeiro

limite permitido, dívidas confessadas não lançadas no passivo e desequilíbrio entre a previsão e a realização das receitas e despesas (MACEDO, 2005).

Para que os gestores públicos municipais deixem de ser apontados como o "lobo mau" da gestão pública nacional, é indispensável que os princípios da administração pública proclamados na Carta Magna sejam efetivamente valorizados e consagrados nas administrações municipais (GARRIDO, 2008). Ainda importante destacar que, mesmo reconhecendo-se a evolução positiva quanto ao índice de aprovação de contas, a qual favorece a gestão fiscal responsável, não se pode esquecer quanto à importância da divulgação do desempenho dos governos municipais especialmente quanto ao atendimento das necessidades públicas locais (RAUSCH; SOARES, 2010).

\subsection{Tribunal de Contas}

Os Tribunais de Contas são órgãos autônomos, independentes, constitucionalmente estabelecidos, totalmente desprendidos de qualquer ligação de condicionamento com os poderes federativos, proporcionando subsídio, de natureza operacional e em algumas situações exclusivas ao poder legislativo (COSTA, 2005). Os Tribunais de Contas Estaduais auxiliam os poderes legislativos na fiscalização contábil, financeira e orçamentária dos poderes públicos constitucional, emitindo pareceres prévios sobre as contas apresentadas pelos gestores públicos em seu exercício (BIRCK; SHIKIDA; SCHALLENBERGER, 2004).

De acordo com o art. 71 da Constituição Federal do Brasil de 1988, cabem ao Tribunal de Contas da União mediante do parecer prévio, apreciar as contas prestadas anualmente pelo Presidente da República, julgar as contas dos administradores e demais responsáveis por dinheiros, bens e valores públicos da administração direta e indireta, fiscalizar a aplicação de quaisquer recursos repassados pela União mediante convênio, a Estado, ao Distrito Federal ou a Município, e entre outras funções de sua competência. $\mathrm{O}$ art. 75 da CF estabelece que as normas de competência do TCU apliquem-se aos Tribunais de Contas dos Estados e do Distrito Federal, bem como os Tribunais e Conselhos de Contas dos Municípios.

Perante o Tribunal de Contas da União e dos Tribunais de Contas Estaduais, a fiscalização na prestação de contas incidirá sobre qualquer pessoa física ou jurídica, pública ou privada, que utilize, arrecade, guarde, gerencie ou administre dinheiros, bens e valores públicos ou pelos quais a União responda, ou que, em nome desta, assuma obrigações de 
Análise dos apontamentos do TCE-MT nas contas públicas dos municípios da região Médio Norte do Gato Grosso

Roberto Alves Cabral

Magno Alves Ribeiro

natureza pecuniária (BRASIL, 1988). Aos que manejam o capital público, deve ser apoiado e orientado pelos Tribunais de Contas, isso é fundamental para a apuração de possíveis irregularidades daqueles que derem causa à perda, ao extravio ou a outra irregularidade de que resulte lesão ao tesouro público (ALBUQUERQUE, 2006).

Com a chegada da LRF, os Tribunais de Contas receberam novas atribuições, o que obrigaram a adquirirem uma melhor preparação técnica para seguir as inovações trazidas tanto nos instrumentos de planejamento, quanto na execução orçamentária, principalmente na verificação de cumprimentos de limites de gastos (VALINO, 2010). A verificação quanto aos cumprimentos da LRF é de competência dos Tribunais de Contas, fundada sobre alguns pilares, dentre eles, a transparência (SANTOS et al, 2010).

\subsubsection{Tribunal de Contas do Estado de Mato Grosso}

As atribuições do Tribunal de Contas do Estado de Mato Grosso (TCE-MT) são regidas atualmente na Lei Complementar $n^{\circ}$ 269, de 22 de janeiro de 2007, revogando a anterior Lei Complementar $n^{\circ} 11$ de 1991. Sua principal função é mencionada no próprio site do Portal do TCE-MT, sendo que:

A principal função é a de fiscalizar a legalidade, legitimidade e economicidade das despesas públicas, ou seja, acompanhar a correta aplicação dos recursos públicos para que as taxas e impostos recolhidos retornem para a sociedade em serviços de qualidade como, saúde, educação, segurança, etc.

No inciso I do art. $1^{\circ}$ da LC 269/2007, regulamenta que incumbe ao TCE-MT sobre a emissão de parecer prévio circunstanciado sobre as contas prestadas anualmente pelo Governador do Estado e pelos Prefeitos Municipais. A emissão do parecer prévio sobre as contas dos prefeitos será até o final do exercício financeiro seguinte à sua execução, as prestações de contas e os respectivos pareceres prévios, evidenciarão os principais aspectos da gestão fiscal como parte integrante da avaliação anual, sendo objetos de ampla divulgação, inclusive por meio eletrônico, ficando disponíveis para consulta de qualquer interessado depois do trânsito em julgado (MATO GROSSO, 2007-1).

O parecer prévio pode ser definido como um documento que contém a análise técnica e formal, feita pelo Tribunal de Contas da União, pelos Tribunais de Contas Estaduais e Municipais sobre determinados aspectos das contas prestadas anualmente pelos chefes dos Poderes Executivos, análise esta que orientará o Poder Legislativo no julgamento dessas contas (ANDRADA; BARROS, 2010). Contudo, prestar contas não significa apenas a 
Análise dos apontamentos do TCE-MT nas contas públicas dos municípios da região Médio Norte do Gato Grosso

Roberto Alves Cabral

Magno Alves Ribeiro

disponibilização de um rol de documentos ao fim de cada exercício, mas a demonstração correta de todas as realizações da administração, informando o montante arrecadado, quanto se gastou, em que se gastou e quais os resultados alcançados (MATO GROSSO, 2007-2).

A atual Resolução no. 14/2007, que institui o Regimento Interno do TCE-MT, regulamenta os trabalhos de fiscalização do TCE-MT, ao qual subsidiam a emissão do parecer prévio sobre as contas prestadas pelos prefeitos municipais. As apreciações das contas são desempenhadas por relatores e suas equipes no próprio município, onde são examinadas as informações cedidas pelas prefeituras referentes os demonstrativos contábeis, financeiros, patrimoniais, orçamentários e de resultados. Essas informações são transmitidas aos sistemas informatizados LRF-Cidadão e APLIC para gerar o relatório de auditoria.

\section{METODOLOGIA}

Este estudo aborda uma pesquisa de natureza qualitativa de caráter descritivo, utilizando-se de documentos eletrônicos na obtenção dos dados, da revisão bibliográfica da legislação e de outros estudos nesse campo. Para Sampieri, Collado e Lucio (2006, p. 10), "em termos gerais, os estudos qualitativos envolvem a coleta de dados utilizando técnicas que não pretendem medir nem associar as medições a números, [...]".

Em si, esta pesquisa objetiva analisar as contas públicas dos municípios da região Médio Norte do estado de Mato Grosso, sob o enfoque de identificar irregularidades na transparência e responsabilidade dos gestores municipais no cumprimento das exigências legais trazidos pela Lei de Responsabilidade Fiscal (LRF). Essa análise será realizada a partir das informações apresentadas no parecer prévio das contas públicas anuais das prefeituras, sendo essas informações disponibilizadas e abertas ao cidadão através do site do Tribunal Contas do Estado de Mato Grosso (TCE-MT).

A fonte para a coleta dos dados será no próprio portal eletrônico do TCE-MT, no qual serão utilizadas informações extraídas dos relatórios técnicos decorrentes de auditoria das contas públicas anuais dos municípios. Para realização desta pesquisa, foram utilizados os relatórios dos exercícios financeiros publicados entre os anos de 2006 à 2010, na delimitação do universo, foram selecionados 10 municípios localizados geograficamente na região Médio Norte do estado de Mato Grosso, estando divididos em duas regiões de planejamento. $\mathrm{Na}$ região VIII Oeste, selecionou os municípios de Barra do Bugres, Denise, Nova Olímpia, Porto 
Análise dos apontamentos do TCE-MT nas contas públicas dos municípios da região Médio Norte do Gato Grosso

Roberto Alves Cabral

Magno Alves Ribeiro

Estrela, Santo Afonso e Tangará da Serra (Cidade Pólo), e na região IX Centro-Oeste, selecionou os municípios de Alto Paraguai, Arenápolis, Nortelândia e Nova Marilândia.

Para responder ao problema proposto nesta pesquisa, foram utilizados no quadro 01 critérios para atingir o resultado final destacando as principais irregularidades em relação à LRF nos pareceres prévios das contas dos municípios. Após serem identificadas as irregularidades, serão selecionadas por artigos as infrações que mais apareceram durante os cinco anos pesquisados.

Quadro 01. Critérios para seleção das principais irregularidades.

\begin{tabular}{|c|l|}
\hline Critério & \multicolumn{1}{|c|}{ Descrição } \\
\hline $1^{\text {o }}$ & $\begin{array}{l}\text { Os artigos que apresentarem a somatória de 10 ou mais infrações, não devendo exceder o } \\
\text { máximo de 10 artigos. }\end{array}$ \\
\hline $2^{\text {o }}$ & $\begin{array}{l}\text { No caso de exceder o número de 10 artigos com mais de 10 infrações, serão selecionados } \\
\text { apenas os 10 primeiros com o maior número de irregularidades. }\end{array}$ \\
\hline $3^{\text {o }}$ & $\begin{array}{l}\text { No caso de não haver artigos com mais de 10 irregularidades, serão selecionados apenas os 10 } \\
\text { primeiros artigos que apresentarem a maior quantidade de infrações gravíssimas, graves e não } \\
\text { classificadas. }\end{array}$ \\
\hline $4^{\text {o }}$ & $\begin{array}{l}\text { No caso de não haver mais de 10 artigos identificados em infrações, esses mesmos serão } \\
\text { selecionados. }\end{array}$ \\
\hline
\end{tabular}

Esses critérios do quadro 01 serão utilizados apenas para seleção das principais irregularidades, diferente dos critérios adotados para classificação dos municípios infratores nos artigos da LRF. Os critérios aplicados para definição da colocação de cada município será medido pela natureza da gravidade das transgressões praticadas pelos municípios, ou seja, os primeiros colocados serão as gestões que mais apresentarem irregularidades gravíssimas, para critério de desempate passam a utilizar as irregularidades graves, e por último na persistência de igualdade de infração a valer das irregularidades não classificadas.

\section{RESULTADOS}

\subsection{Dados do Estado e dos municípios em pesquisa}

Localizado na região Centro-Oeste do território brasileiro, o Estado de Mato Grosso é o terceiro maior estado do país em extensão territorial e o décimo primeiro lugar no ranking de estados com maior área urbana. No último levantamento do Censo realizado em 2010, Mato Grosso possui 3.035.122 habitantes, o que representa 1,59\% da população brasileira. De 
Análise dos apontamentos do TCE-MT nas contas públicas dos municípios da região Médio Norte do Gato Grosso

Roberto Alves Cabral

Magno Alves Ribeiro

acordo com as informações do Instituto Brasileiro de Geografia e Estatística (IBGE) em parceria com a Secretaria de Estado de Planejamento e Coordenação Geral (SEPLAN-MT), no ano de 2008, Mato Grosso apresentou um PIB per capita no valor de R \$ 17.927,00, obtendo a $7^{\mathrm{a}}$ posição no ranking dos estados brasileiros com maior PIB per capita.

O Estado de Mato Grosso possui atualmente 141 municípios, reunidos em 22 microrregiões político-administrativas, que fazem parte de 5 mesorregiões definidas pelo IBGE. Através de estudos elaborados pela SEPLAN-MT no ano de 2001, foi determinada uma nova regionalização do Estado, definindo 12 Regiões de Planejamento. Para a pesquisa, foram especificados 10 municípios do Estado de Mato Grosso, localizados na região Médio Norte geográfico do Estado e nas regiões Oeste e Centro-Oeste das 12 Regiões de Planejamento.

$\mathrm{Na}$ tabela 01, foram utilizadas informações gerais de contagem e indicadores para caracterizar cada município. Os dados geográficos são apresentados pela quantidade da população e extensão territorial $\left(\mathrm{Km}^{2}\right)$, medidos pelo IBGE, para o indicador social serviu-se do Índice de Desenvolvimento Humano Municipal (IDH-M), organizado através do Programa das Nações Unidas para o Desenvolvimento (PNUD). Para os indicadores econômicos, utilizaram-se os dados do Produto Interno Bruto (PIB) per capita, o Índice de Participação dos Municípios (IPM) e o Coeficiente Individual de Fundo de Participação do Município (CIFPM), divulgados respectivamente pelo IBGE, Secretaria de Estado de Fazenda do Mato Grosso (SEFAZ-MT) e Tribunal de Contas da União (TCU).

Tabela 01. Dados econômicos, geográficos e sociais dos municípios em pesquisa.

\begin{tabular}{ccccccc}
\hline Município & População & Ext. Ter. $\left(\mathbf{k m}^{2}\right)$ & IDH $-\mathbf{M}$ & PIB $*$ & IPM & CIFPM \\
\hline Alto Paraguai & 8.726 & 2.053 & 0,704 & $7.826,39$ & 0,145463 & 0,6 \\
\hline Arenápolis & 9.353 & 415 & 0,721 & $8.205,63$ & 0,155064 & 0,8 \\
\hline Barra do Bugres & 29.847 & 7.229 & 0,715 & $12.142,63$ & 1,104143 & 1,6 \\
\hline Denise & 8.205 & 1.301 & 0,736 & $10.127,11$ & 0,226060 & 0,6 \\
\hline Nortelândia & 6.147 & 1.351 & 0,718 & $11.040,92$ & 0,147920 & 0,6 \\
\hline Nova Marilândia & 2.803 & 1.943 & 0,701 & $16.458,43$ & 0,179831 & 0,6 \\
\hline Nova Olímpia & 17.135 & 1.568 & 0,742 & $11.065,64$ & 0,805109 & 1,2 \\
\hline Porto Estrela & 3.635 & 2.065 & 0,654 & $10.058,82$ & 0,188408 & 0,6 \\
\hline Santo Afonso & 2.737 & 1.170 & 0,728 & $12.058,82$ & 0,122858 & 0,6 \\
\hline Tangará da Serra & 81.918 & 11.566 & 0,780 & $16.052,75$ & 2,127733 & 2,8 \\
\hline Fonte: IBGE (2010; 2011$) ;$ PNUD $(2000) ;$ SEFA7-MT $(2011) ;$ TCU $(2011) * *$ Per capita (R\$) &
\end{tabular}

Fonte: IBGE (2010; 2011); PNUD (2000); SEFAZ-MT (2011); TCU (2011). * Per capita (R\$) 
Análise dos apontamentos do TCE-MT nas contas públicas dos municípios da região Médio Norte do Gato Grosso

Roberto Alves Cabral

Magno Alves Ribeiro

Nas informações contidas da tabela 01, observa-se o destaque do município de Tangará da Serra entre todos os municípios levantados neste estudo, no qual os seus dados apresentaram uma considerável diferença geográfica, social e econômica dos demais municípios, ficando apenas com o PIB per capita inferior a do município de Nova Marilândia.

\subsection{Análise e discussões dos resultados}

Nesta seção abordaram-se os resultados encontrados a partir da coleta de dados, bem como a análise e a discussão das informações acerca do problema e dos objetivos propostos, aplicando nas informações os métodos e os critérios definidos na metodologia da pesquisa.

Os dados coletados que serão demonstrados na seqüência desta pesquisa, são de divulgação pública do TCE-MT através de seu site, as informações encontradas estão presentes no relatório de auditoria das contas anuais dos municípios, tendo esse relatório o objetivo de subsidiar a emissão do Parecer Prévio sobre as Contas de Governo prestadas pelo Chefe do Poder Executivo Municipal.

Na tabela 02, é demonstrada a quantidade de irregularidades em relação a LRF que foram apontadas pelo TCE-MT no período de 2006 à 2010, as informações dessa tabela é o somatório das infrações classificadas em gravíssimas, graves e não classificadas, enquadradas nos artigos da LC n $\mathrm{n}^{\mathrm{0}}$ 101/2000, juntamente com as infrações ocasionadas pelas gestões municipais em desconformidade com o Sistema de LRF-Cidadão. As apurações desses dados ocorreram por meio da análise de 10 relatórios ano a ano durante o período pesquisado, utilizando por ano um relatório para cada município.

Tabela 02. Quantidade de irregularidades por municípios no período de 2006 à 2010.

\begin{tabular}{|c|c|c|c|c|c|c|}
\hline & \multicolumn{3}{|c|}{ Gestão 2005/2008 } & \multicolumn{2}{|c|}{ Gestão 2009/2012 } & \multirow[b]{2}{*}{ Total } \\
\hline & 2006 & 2007 & 2008 & 2009 & 2010 & \\
\hline Alto Paraguai & 9 & 7 & 11 & 5 & 4 & 36 \\
\hline Arenápolis & 7 & 9 & 1 & 7 & 3 & 27 \\
\hline Barra do Bugres & 5 & 5 & 3 & 11 & 4 & 28 \\
\hline Denise & 2 & 6 & 1 & 3 & 6 & 18 \\
\hline Nortelândia & 5 & 1 & 6 & 4 & 4 & 20 \\
\hline Nova Marilândia & 1 & 3 & 0 & 3 & 6 & 13 \\
\hline Nova Olímpia & 1 & 1 & 2 & 4 & 2 & 10 \\
\hline Porto Estrela & 3 & 3 & 1 & 9 & 2 & 18 \\
\hline Santo Afonso & 4 & 2 & 0 & 2 & 6 & 14 \\
\hline
\end{tabular}

Volume 1, Número 2 
Análise dos apontamentos do TCE-MT nas contas públicas dos municípios da região Médio Norte do Gato Grosso

Roberto Alves Cabral

Magno Alves Ribeiro

\begin{tabular}{cccccccc}
\hline \hline Tangará da Serra & 2 & 3 & 4 & 8 & 5 & $\mathbf{2 2}$ \\
\hline Total & $\mathbf{3 9}$ & $\mathbf{4 0}$ & $\mathbf{2 9}$ & $\mathbf{5 6}$ & $\mathbf{4 2}$ & $\mathbf{2 0 6}$ \\
\hline
\end{tabular}

Nos resultados do ano de 2006, foram identificados o total de 39 infrações no geral com a LRF nas prestações de contas, sendo que 19 irregularidades estavam voltadas nos artigos da LC 101/2000 e 20 infrações com a LRF-Cidadão. Entre os artigos que mais houve ocorrências de irregularidades estão o art. 11, com 5 infrações, os artigos 42, 48 e 50 com respectivamente 2 infrações cada. Entre os municípios, Alto Paraguai apresentou a maior quantidade de irregularidades, no total foram 9, seguido por Arenápolis com 7, os municípios que apresentaram um número menor de irregularidades foram Nova Marilândia e Nova Olímpia com apenas uma infração cada, sendo que todos os municípios apresentaram nesse ano pelo menos uma ou mais irregularidades com a LRF nas prestações de contas.

Nos primeiros relatórios analisados, identificou-se a maior participação das infrações envolvendo o art. 11 da LRF, e de acordo com a LC 101/2000 esse artigo "constituem requisitos essenciais da responsabilidade na gestão fiscal a instituição, previsão e efetiva arrecadação de todos os tributos da competência constitucional do ente da Federação". A infração do art. 11 não foi classificada nos critérios de grau de gravidade do TCE-MT para a apreciação das contas anuais, tendo aos prefeitos dos municípios de Alto Paraguai, Arenápolis, Barra do Bugres, Denise e Santo Afonso a prestarem esclarecimentos quanto a não efetiva cobrança e arrecadação dos tributos da competência constitucional do município.

Em publicação no Tribunal de Contas do Estado do Rio de Janeiro, Araújo (2009) destaca que mesmo da pequena participação da receita própria, os municípios não podem prescindir da efetiva arrecadação dos tributos de sua competência, indicando que os principais problemas quanto a arrecadação de tributos municipais possa estar na ausência de infraestrutura adequada nos setores que gerenciam os créditos públicos, como a carência de recursos humanos, materiais e sistemas informatizados.

Ainda sobre as irregularidades do ano de 2006, o maior número de infrações está voltado para a LRF-Cidadão, onde verificou que os encaminhamentos dos informes bimestrais estavam fora do prazo estabelecido pelo TCE-MT e muitas divergências de valores no LRF-Cidadão com os informados nos demonstrativos publicados pelas prefeituras. Esses apontamentos nos relatórios podem estar associado ao fato de que grande parte dos municípios, 7 dos 10, não apresentarem o Sistema de Controle Interno (SCI), ao qual os relatores constataram que os municípios de Alto Paraguai, Arenápolis, Denise, Nortelândia, 
Análise dos apontamentos do TCE-MT nas contas públicas dos municípios da região Médio Norte do Gato Grosso

Roberto Alves Cabral

Magno Alves Ribeiro

Nova Olímpia, Porto Estrela e Santo Afonso não possuíam controladores internos e as Unidades de Controle Interno (UCI).

Na pesquisa de Silva e Filho (2008) com as prestações de contas nas prefeituras de Pernambuco no ano de 2000 a 2005, do total das ressalvas analisadas, $45 \%$ delas corresponderam a falhas nos procedimento de controle interno. Em outro estudo realizado por Santos e Muraro (2008), verificaram que 39\% dos municípios localizados no Corede Produção do Rio Grande do Sul, informaram que o setor de controle interno ainda não consegue realizar um acompanhamento constante das atividades atribuídas por lei.

Em análise no ano de 2007, identificou nos relatórios de auditoria das contas o total de 40 irregularidades sobre a gestão fiscal dos municípios, dessas irregularidades, 31 infrações estavam relacionadas com os artigos da LC 101/2000, e as outras 9 infrações foram identificadas em descumprimentos ao Sistema LRF-Cidadão. Na comparação dos dados desse ano com o de 2006, a quantidade total de irregularidades pouco se alterou, passou de 39 irregularidades de 2006 para 40 em 2007, induzindo a entender que os gestores e suas gestões municipais pouco se atentaram nos alertas emitidos pelo TCE-MT quanto o melhoramento das prestações de contas públicas.

É importante de se destacar que diferente do ano de 2006, no ano de 2007 o número de infrações nos artigos da LC 101/2000 foram maiores em relação as transgressões apontadas para o Sistema LRF-Cidadão, destacando 4 irregularidades para os artigos $9^{\circ}$, 11 e 48 , e 3 irregularidades para os artigos 50 e 59 da LRF. Novamente os municípios de Alto Paraguai, com 7 infrações, e Arenápolis, com 9 infrações, apresentaram a maior quantidade de irregularidades, já os municípios de Nortelândia e Nova Olímpia foram os que apresentaram menor quantidade, 1 irregularidade para cada.

Com relação as irregularidades, no art. $9^{\circ}$ verificou que os municípios de Alto Paraguai e Barra do Bugres não informaram a realização de audiência pública, descumprindo o parágrafo $4^{\circ}$ desse artigo, logo os municípios de Denise e Nova Marilândia apresentaram déficit de execução orçamentária. Hanaoka et al (2011), demonstraram várias administrações municipais que apresentaram déficit orçamentário elevado, nas prestações de contas de 16 prefeituras do Vale do Ribeira no estado de São Paulo, referente aos exercícios de 1992 a 2008. Conforme esse estudo, do ano de 2005 a 2008, entre os principais motivos de pareceres desfavoráveis foram com o déficit orçamentário, o que segundo os autores, contrariando o principal motivo da criação da LRF referente ao equilíbrio das contas públicas. 
Análise dos apontamentos do TCE-MT nas contas públicas dos municípios da região Médio Norte do Gato Grosso

Roberto Alves Cabral

Magno Alves Ribeiro

No art. 48 da LRF, foram apontadas ausências dos instrumentos de transparência da gestão fiscal em 4 municípios. Em relação a desconformidade no art. 48 da LRF, Souza et al (2008) produziram um estudo sobre o atendimento desse artigo no Estado de Minas Gerais, visando analisar se os municípios mineiros divulgam a transparência da sua gestão pública através da internet. Nesse estudo foi realizado com uma amostra de 85 municípios, sendo concluído que somente cerca de $35 \%$ dos gestores públicos mineiros utilizavam a internet para evidenciar as informações demandadas pela LRF.

Diferente dos resultados observados nos relatórios dos anos anteriores, o ano de 2008 demonstrou um número menor de irregularidades, ao total foram identificados 29 irregularidades, sendo 26 infrações nos artigos da LC 101/2000 e 3 infrações ao Sistema LRFCidadão, dessas infrações ao Sistema LRF-Cidadão, todas encontradas no município de Alto Paraguai. Esse mesmo município foi o que mais apresentou irregularidades com a LRF no ano de 2008, no total foram 11 irregularidades, um número bem expressivo em comparação com os demais municípios, o segundo município em números de irregularidades foi Nortelândia com 6 infrações.

Nos relatórios do ano de 2008, não foram apontadas nenhuma irregularidade em desconformidade a LRF nas contas anuais dos municípios de Nova Marilândia e Santo Afonso. As infrações da LC 101/2000 que mais apareceram nos relatórios de 2008 foram em relação ao art. 50, com 9 infrações ao todo, e o art. $9^{\circ}$, com 7 infrações. Nos balanços dos municípios de Barra do Bugres, Nortelândia, Nova Olímpia e Tangará da Serra foram constatados fatos contábeis registrados indevidamente ou não contabilizados, enquadrados em desacordo ao art. 50 da LRF, no qual menciona que as escriturações das contas públicas deverão obedecer as normas de contabilidade pública e o incisos que compete ao artigo.

Em destaque ao descumprimento do art. $9^{\circ}$, os municípios de Alto Paraguai, Denise, Nortelândia, Porto Estrela e Tangará da Serra apresentaram irregularidades sobre a gestão municipal ao não informarem a realização de audiência pública para análise do cumprimento das metas fiscais de cada quadrimestre. Essa irregularidade também foi identificada por Söthe, Söthe e Gubiani (2011) em pesquisa nas contas públicas dos governos municipais do Estado do Rio Grande do Sul, ao qual verificaram que no exercício de 2007, a matéria de segunda maior incidência de parecer pelo não atendimento da LRF foi relacionada a não realização das audiências públicas em oito municípios. 
Análise dos apontamentos do TCE-MT nas contas públicas dos municípios da região Médio Norte do Gato Grosso

Roberto Alves Cabral

Magno Alves Ribeiro

No ano de 2009, foi observado que houve mais incidências de irregularidades nesse ano do que os outros anos analisados anteriormente. Analisando os relatórios dos municípios em 2009, foi possível identificar ao todo 56 irregularidades, sendo apontados 54 infrações com os artigos da LC 101/2000 e 2 infrações com o Sistema LRF-Cidadão. Nesse ano, todos os municípios apresentaram mais que uma irregularidade, entre os municípios que mais infringiram a LRF foram Barra do Bugres, Porto Estrela e Tangará da Serra, com 11, 9 e 8 irregularidades respectivamente, e os municípios que menos infringiram a LRF foram Santo Afonso, com 2 infrações, Denise e Nova Marilândia, 3 infrações para cada.

A maior incidência de irregularidade foi identificada no art. $5^{\circ}$ da LRF, sendo apontadas 9 irregularidades, envolvendo 6 municípios dos 10 em pesquisa, as infrações relatadas foram de descumprimento aos incisos I e III desse artigo, relatando ausência dos demonstrativos e impropriedades na análise do processo da Lei Orçamentária Anual (LOA), e a ausência de comprovação de que a reserva de contingência tenha sido utilizada para cobrir passivos contingentes e outros riscos fiscais. Como já mencionado nos anos anteriormente, os $\operatorname{artigos} 9^{\circ}, 48$ e 50 são reincidentes nas irregularidades, contendo 8 infrações para 0 art. $9^{\circ}$ e 6 infrações para os artigos 48 e 50 .

E por fim, na última análise dos anos pesquisados, em 2010 foi observado que o número total de irregularidades é menor do que a quantidade demonstrada no ano de 2009, mas com o total de 42 infrações levantadas, torna como o segundo ano que mais relatou irregularidades com a LRF nos relatórios de auditoria utilizados nesta pesquisa. Todas as 42 irregularidades foram identificadas com os artigos da LC 101/2000, não havendo registro de incidências em desconformidade com a LRF-Cidadão. Os municípios de Denise, Nova Marilândia e Santo Afonso foram os que mais cometeram infrações, 6 para cada, e os municípios de Nova Olímpia e Porto Estrela apresentaram 2 infrações cada.

É interessante perceber que as infrações cometidas pelas gestões municipais nesse ano de 2010 concentraram em poucos artigos da LC 101/2000, dos 42 casos de irregularidades abordados, 37 estão voltados para os artigos $1^{\circ}, 9^{\circ}$, com 10 infrações cada, o art. 48 com 7 infrações e os artigos 11 e 49 com 5 infrações cada. Os relatórios de auditoria indicaram para os municípios que infringiram o art. $1^{\circ}$ da LRF, descrevendo como ausência da transparência de contas públicas e a não adoção de providências para constituição e arrecadação do crédito tributário. 
Análise dos apontamentos do TCE-MT nas contas públicas dos municípios da região Médio Norte do Gato Grosso

Roberto Alves Cabral

Magno Alves Ribeiro

Em análise, a pesquisa de Söthe, Söthe e Gubiani (2011), levantados os dados apurados no ano de 2005, eles também identificaram problemas que levaram à emissão do parecer pelo não-atendimento no art. $1^{\circ}$ da LRF, dos 75 poderes executivos municipais, 60 apresentaram situação de desequilíbrio financeiro, o excesso de despesa com pessoal, falta de publicação de relatórios e entrega de relatórios fora do prazo.

Sobre o art. 49 da LRF, os relatores de auditoria mencionaram sobre as contas prestadas pelo Chefe do Poder Executivo, que não foram colocadas à disposição dos cidadãos na Câmara Municipal e no órgão técnico responsável pela sua elaboração. Nessas irregularidades do art. 49, o TCE-MT classificou em infração grave esse descumprimento dos gestores municipais, sendo que essas transgressões a transparência nas contas públicas e a sua não disponibilização aos cidadãos, fere um dos principais motivos da existência da LRF.

Ainda em referência o art. 49 da LRF, em 2008, o Ministério Público do Estado do Maranhão - MPMA acionaram prefeitos de dois municípios do estado por desobedecerem a obrigação legal do envio de cópia da prestação de contas dos municípios à Câmara Municipal de cada cidade, referente ao exercício de 2007. Na ação, o promotor de justiça argumentou a notória violação frontal ao princípio da legalidade, ao descumprir no artigo 31 da Constituição Federal e o artigo 49 da Lei Complementar n 101/2000 (GOMES, 2008).

Ao final dos cinco anos analisados nesta pesquisa, um dos pontos a serem destacados pela quantidade de irregularidades identificadas são em relação os anos de 2008 e 2009, no qual nesses anos apresentaram a maior diferença no número de infrações entre os anos pesquisados, sendo que no ano de 2008 foram identificadas ao todo 29 irregularidades nas contas públicas dos municípios, e no ano de 2009, identificou no total 56 infrações, o que correspondeu uma diferença de aproximadamente $93,10 \%$ a mais de um ano para o outro.

O quadro 02 destaca os artigos da LRF que incidiram irregularidades cometidas pelas gestões municipais no período da pesquisa que foi do ano de 2006 à 2010, essas infrações foram apontadas pelos relatores do TCE-MT no julgamento das prestações de contas públicas dos municípios. As irregularidades apontadas são classificadas conforme a natureza da gravidade em infração a lei, de acordo com a Instrução Normativa ${ }^{\circ} 02$ de 2006 do TCE-MT, que vigorou para apreciação das contas estadual e municipal até o ano de 2010.

Quadro 02. Número de irregularidades por artigos da LRF.

\begin{tabular}{|c|c|c|c|c|}
\hline \multirow{2}{*}{ Artigo } & \multicolumn{3}{|c|}{ Classificação } & \multirow{2}{*}{$\mathbf{N}^{0}$ Itens } \\
\hline & Gravíssima & Grave & Não Classif. & \\
\hline
\end{tabular}

Volume 1, Número 2 Jul./dez. 2012

\begin{tabular}{|c|c|c|c|c|}
\hline \multirow{2}{*}{ Artigo } & \multicolumn{3}{|c|}{ Classificação } & \multirow{2}{*}{$\mathbf{N}^{o}$ Itens } \\
\hline & Gravíssima & Grave & Não Classif. & \\
\hline
\end{tabular}
Revista UNEMAT de Contabilidade UNEMAT 
Análise dos apontamentos do TCE-MT nas contas públicas dos municípios da região Médio Norte do Gato Grosso

Roberto Alves Cabral

Magno Alves Ribeiro

\begin{tabular}{|c|c|c|c|c|}
\hline $1^{\mathbf{o}}$ & 2 & 13 & 1 & 16 \\
\hline $4^{\mathbf{o}}$ & 1 & 1 & 4 & 6 \\
\hline $5^{\mathbf{o}}$ & 0 & 2 & 9 & 11 \\
\hline $7^{\mathbf{o}}$ & 0 & 0 & 1 & 1 \\
\hline $9^{\mathbf{o}}$ & 8 & 10 & 12 & 30 \\
\hline 11 & 0 & 7 & 12 & 19 \\
\hline 14 & 0 & 2 & 3 & 5 \\
\hline 15 & 0 & 0 & 1 & 1 \\
\hline 16 & 0 & 1 & 1 & 2 \\
\hline 17 & 0 & 1 & 0 & 1 \\
\hline 20 & 1 & 1 & 0 & 2 \\
\hline 21 & 0 & 0 & 1 & 1 \\
\hline 22 & 0 & 0 & 3 & 3 \\
\hline
\end{tabular}

\begin{tabular}{|c|c|c|c|c|}
\hline 25 & 0 & 0 & 1 & 1 \\
\hline 26 & 0 & 0 & 1 & 1 \\
\hline 30 & 0 & 0 & 1 & 1 \\
\hline 32 & 0 & 1 & 0 & 1 \\
\hline 42 & 2 & 1 & 4 & 7 \\
\hline 48 & 0 & 1 & 20 & 21 \\
\hline 49 & 0 & 7 & 1 & 8 \\
\hline 50 & 0 & 10 & 10 & 20 \\
\hline 52 & 0 & 0 & 3 & 3 \\
\hline 54 & 0 & 1 & 1 & 2 \\
\hline 59 & 0 & 1 & 6 & 7 \\
\hline 62 & 0 & 0 & 1 & 1 \\
\hline 63 & 0 & 0 & 1 & 1 \\
\hline
\end{tabular}

Aplicando o método do critério de seleção para identificar quais são as principais irregularidades da LRF, no quadro 01 foi observado 6 artigos que apresentaram mais de 10 infrações durante o período pesquisado, enquadrando esses artigos no $1^{\circ}$ critério para seleção das principais irregularidades tratadas nesta pesquisa.

No gráfico 01, foi demonstrada a distribuição em percentual desses artigos em relação ao total de irregularidades de todos os artigos da LRF identificados.

\section{Gráfico 01. Principais irregularidades com a LRF.}

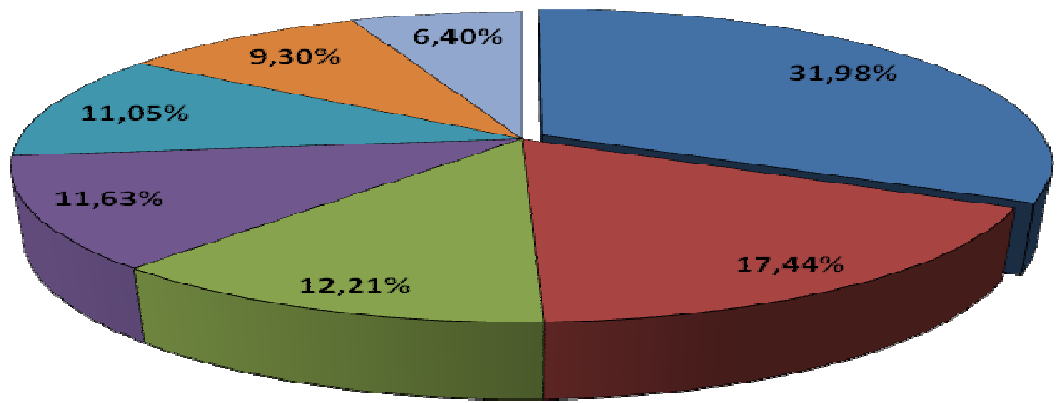

口Demais artigos $\square$ art. $9^{\circ} \square$ art. 48 art. 50 art .11 $\square$ art. $1^{\circ} \square$ art. $5^{\circ}$

Conforme o gráfico 01 , o artigo $9^{\circ}$ da LRF figurou sendo o artigo com a maior participação de infrações das gestões municipais nesse período pesquisado, também foi o artigo que mais foi apontado irregularidades gravíssimas, observado no quadro 02. Nas irregularidades gravíssimas desse artigo, os descumprimentos cometidos em algumas das gestões municipais envolveram com o déficit de execução orçamentária, sendo empenhadas 
Análise dos apontamentos do TCE-MT nas contas públicas dos municípios da região Médio Norte do Gato Grosso

Roberto Alves Cabral

Magno Alves Ribeiro

despesas sem os correspondentes recursos para acobertá-las, em desconformidade com as metas de resultado do Anexo de Metas Fiscais.

Na tabela 03, são observados os municípios e a posição de cada ocupado no ranking elaborado para demonstrar as gestões que provocaram mais infrações aos artigos da LRF, segundo a gravidade apontada para cada infração.

Tabela 03. Ranking dos municípios infratores da LRF.

\begin{tabular}{ccccccc}
\hline Coloc. & Município & Gravíssima & Grave & Não Classif. & LRF-Cidadão & Total \\
\hline $1^{\circ}$ & Denise & 4 & 3 & 9 & 2 & $\mathbf{1 8}$ \\
\hline $2^{\circ}$ & Barra do Bugres & 3 & 13 & 7 & 5 & $\mathbf{2 8}$ \\
\hline $3^{\circ}$ & Arenápolis & 2 & 9 & 12 & 27 \\
\hline $4^{\circ}$ & Nova Marilândia & 2 & 6 & 3 & 4 & $\mathbf{1 3}$ \\
\hline $5^{\circ}$ & Tangará da Serra & 1 & 12 & 5 & $\mathbf{2 2}$ \\
\hline $6^{\circ}$ & Alto Paraguai & 1 & 6 & 20 & 3 & $\mathbf{3 6}$ \\
\hline $7^{\circ}$ & Porto Estrela & 1 & 2 & 12 & 1 & $\mathbf{1 4}$ \\
\hline $8^{\circ}$ & Santo Afonso & 0 & 6 & 7 & 13 & 3 \\
\hline $9^{\circ}$ & Nortelândia & 0 & 4 & 7 & $\mathbf{2 0}$ \\
\hline $10^{\circ}$ & Nova Olímpia & 0 & 2 & 1 & $\mathbf{1 0}$ \\
\hline
\end{tabular}

Para efeito de análise aplicada nesta pesquisa, adotou na tabela 03, o método de classificação conforme a natureza de gravidade indicada nos relatórios de auditoria, dessa maneira não se utilizou da quantidade de irregularidades identificadas por cada município. No ranking de classificação, as irregularidades gravíssimas foram os primeiros critérios utilizados para colocação geral dos municípios, seguido respectivamente pelas irregularidades graves e não classificadas

Em se tratando de quantidade de irregularidades, pode ser observado que o município de Alto Paraguai foi identificado com o maior número de infrações entre os demais municípios, entretanto, como foram apontadas menos irregularidades gravíssimas, esse município não figurou na primeira colocação do ranking. Por outro lado, obtendo menos infrações em relação a alguns dos municípios, o município de Denise foi classificado como o município campeão em violação a lei, não pelo motivo da quantidade de irregularidades, mas sim pelos agraves transcorridos aos artigos da LRF. 


\section{CONCLUSÃO}

Com os resultados analisados, pode então concluir que as principais irregularidades com a LRF nas contas públicas dos municípios pesquisados foram com 6 artigos, de um total de 26 artigos identificados em infrações ao não atendimento pleno da LC 101/2000. Diante dos critérios adotados para efeito de análise, esses 6 artigos possuíram mais de 10 infrações durante o período pesquisado, adequando-os ao $1^{\circ}$ critério aplicado nesta pesquisa.

Com aproximadamente 68,02\% das irregularidades, os artigos da LC 101/2000 que mais apresentaram infrações foram:

- Art. $9^{\circ}$. Não realização de audiência pública e apresentação de déficit na execução orçamentária;

- Art. 48. Ausências dos instrumentos de transparência da gestão físcal;

- Art. 50. Constatação de fatos contábeis registrados indevidamente ou não contabilizados;

- Art. 11. Não efetiva cobrança e arrecadação dos tributos de competência constitucional do município;

- Art. $1^{\circ}$. Ausências da transparência de contas públicas e não adoção de providências para constituição e arrecadação do crédito tributário;

- Art. $5^{\circ}$. Ausência dos demonstrativos e impropriedades na análise do processo da Lei Orçamentária Anual (LOA), e ausência de comprovação de que a reserva de contingência foi utilizada para cobrir passivos contingentes e outros riscos fiscais.

Nas comparações dos municípios, Alto Paraguai foi o município que mais apresentou irregularidades, entretanto, pelo critério de natureza na gravidade das infrações cometidas, o município de Denise apresentou mais irregularidades gravíssimas, ficando no topo da classificação dos municípios infratores. O município que menos apresentou irregularidades foi Nova Olímpia, esse mesmo, também ficou na melhor colocação dos municípios infratores, apresentando poucas irregularidades graves em relação aos demais municípios.

Por não ter sido encontrado na região um estudo semelhante que aborde os números de ocorrências em irregularidades na LRF, os resultados alcançados ao final desta pesquisa não podem ser decisivos na afirmação se foram favoráveis ou desfavoráveis quanto o nível de 
Análise dos apontamentos do TCE-MT nas contas públicas dos municípios da região Médio Norte do Gato Grosso

Roberto Alves Cabral

Magno Alves Ribeiro

desempenho dos gestores na administração pública, ou se o número de infrações identificadas foram menores ou maiores em relação a média de infrações apuradas nos municípios matogrossenses ou até mesmo com todos os municípios brasileiros.

Essa lacuna aberta servirá para que novas pesquisas sejam intensificadas em apontar os números de irregularidades com a LRF nas contas públicas dos municípios. Outro tema interessante a ser tratado em pesquisas futuras é com relação o Sistema LRF-Cidadão, que durante a pesquisa surgiram infrações em grande número no primeiro ano e depois nos anos seguintes foram diminuindo gradativamente, chegando ao último ano sem apresentar infração, estimulando o pesquisador a levantar questões sobre esse efeito.

\section{REFERÊNCIAS}

ALBUQUERQUE, F. B. Lei de Responsabilidade Fiscal e o Poder Legislativo: uma análise do papel dos tribunais de contas. In: XIV Congresso Nacional do CONPEDI, Fortaleza. Anais... Florianópolis: Fundação Boiteux, 2006.

ANDRADA, A. C. D. de.; BARROS, L. C. de. O parecer prévio como instrumento de transparência, controle social e fortalecimento da cidadania. Revista do Tribunal de Contas do Estado de Minas Gerais. Belo Horizonte, v. 77, n. 4, p. 53-75, dez. 2010.

ARAÚJO, Nina Quintanilha. O controle externo da dívida ativa municipal: A experiência do TCE-RJ (Palestra). In: Encontro com os Prefeitos - Execução Fiscal, 2009. Rio de Janeiro: TCE-RJ, 2009.

BIRCK, L. G.; SHIKIDA, P. F. A.; SCHALLENBERGER, E. O município na Lei de Responsabilidade Fiscal. Revista Brasileira de Gestão de Negócios - FECAP, São Paulo, v. 6, n. 16, p. 15-28, dez. 2004.

BRASIL. Constituição (1988). Constituição da República Federativa do Brasil. Diário Oficial [da] República Federativa do Brasil. Brasília, 1988.

Lei complementar $n^{\circ} .101$, de 04 de maio de 2000. Estabelece normas de finanças públicas voltadas para a responsabilidade na gestão fiscal. Diário Oficial [da] República Federativa do Brasil. Brasília, 2000.

CAMARGO, Maria Emilia; SEHNEM, Alyne. Efeitos da Lei de Responsabilidade Fiscal sobre a prestação de contas das prefeituras catarinenses. RACE - Revista de Administração, Contabilidade e Economia, Santa Catarina, v. 9, n. 1, p. 251-272, jan./dez. 2010.

COSTA, Luiz Bernardo Dias da. O Tribunal de Contas no Estado contemporâneo.

Dissertação de Mestrado, Centro de Ciências Jurídicas e Sociais, PUC, Curitiba, 2005.

DALMONECH, L. F.; TEIXEIRA, A.; SANT'ANNA, J. M. B. O impacto ex-post da Lei de Responsabilidade Fiscal $n^{\circ}$ 101/2000 nas finanças dos estados brasileiros. . RAP - Revista de Administração Pública, Rio de Janeiro, v. 45, n. 4, p. 1173-1196, jul./ago. 2011. 
Análise dos apontamentos do TCE-MT nas contas públicas dos municípios da região Médio Norte do Gato Grosso

Roberto Alves Cabral

Magno Alves Ribeiro

FERNANDES, Márcio Silva. Autonomia municipal na Constituição Federal de 1988. In:

Ensaios sobre impactos da Constituição Federal de 1988 na sociedade brasileira.

Brasília, 2008. Disponível em: <http://bd.camara.gov.br>. Acesso em: 02 de out. 2011.

GARRIDO, Elena. A relação dos municípios com os tribunais de contas e o Ministério

Público: a LRF e a lei de licitações e contratos. In: LINHARES, José (Org.).

Responsabilidade na gestão pública: os desafios dos municípios. Brasília, 2008. Disponível em: <http://bd.Camara.gov.br>. Acesso em: 29 de ago. 2011.

GERIGK, W.; CLEMENTE, A.; TAFFAREL, M. O impacto da LRF sobre a gestão financeira dos pequenos municípios: o caso do Paraná. REPeC - Revista de Educação e Pesquisa em Contabilidade, Brasília, v. 4, n. 3, p. 44-69, set/dez. 2010.

GIRADELO, Luciana. 96 municípios de MT não cumprem LRF. Diário de Cuiabá, Cuiabá, ed. 10677, jul. 2003. Disponível em: <http://www.diariodecuiaba.com.br/detalhe.php?cod= 147588>. Acesso em: 26 de mar. 2012.

GOMES, Johelton. Prefeitos de Esperantinópolis e São Roberto são acionados por improbidade administrativa. MPAM. São Luiz, jun. 2008. Disponível em: <http://www.mp. ma.gov.br/site/DetalhesNoticiaGeral.mtw?noticia_id=616>. Acesso em: 31 de mar. 2012.

HANAOKA, C. H. T. et al. Efeitos da Lei de Responsabilidade Fiscal sobre as prestações de contas de prefeituras do Vale do Ribeira. In: VIII Congresso Virtual Brasileiro de Administração, 2011, São Paulo. Anais... São Paulo: CONVIBRA, 2011.

JAYME JR., F. G.; REIS, J. C. dos; ROMERO, J. P. Restrição orçamentária e Lei de Responsabilidade Fiscal: um estudo para Minas Gerais - 1995-06. Ensaios FEE, Porto Alegre, v. 28, n. 2, p. 409-442, out. 2007.

KOHAMA, Helio. Contabilidade pública: teoria e prática. 10 ed. São Paulo: Atlas, 2006.

MACEDO, Fausto. Justiça impede punição a prefeitos que violam LRF. Gazeta Digital, Cuiabá, maio 2005. Disponível em: <http://www.gazetadigitaLCom.br/conteudo/show/secao/ 10/materia/72387 >. Acesso em: 05 de maio 2012.

MARCUZZO, J. L.; FREITAS, L. A. R. de. A contabilidade gerencial e a Lei de Responsabilidade Fiscal. Revista Eletrônica de Contabilidade Curso de Ciências Contábeis UFSM, Santa Maria, v. 1, n. 1, p. 174-190, set./nov. 2004.

MATO GROSSO. Tribunal de Contas do Estado. Lei complementar $\mathrm{n}^{\circ} 269$, de 22 de janeiro de 2007. Dispõe sobre a Lei Orgânica do Tribunal de Contas do Estado de Mato Grosso e dá outras providências. Diário Oficial [do] Estado de Mato Grosso. Cuiabá, 2007-1.

. Tribunal de Contas do Estado. Transparência na Administração Pública: a serviço da cidadania. Cuiabá: TCE, 2007-2.

MORAES, Alexandre de. Direito Constitucional. 22 ed. São Paulo. Atlas, 2007.

MORAIS, Efraim. Município, o grande ausente na política brasileira. Uma contextualização histórica. In: DANTAS, Bruno. et al (Org.). Constituição de 1988: o Brasil 20 anos depois. Brasília: Senado Federal, Instituto Legislativo Brasileiro, 2008. 
NASCIMENTO, Edson Ronaldo. Lei Complementar 101/2000 - Punições para o descumprimento da Lei de Responsabilidade Fiscal. Revista Jurídica Virtual, Brasília, vol. 3, n. 30, nov./2001. Disponível em: < http://www.planalto.gov.br/ccivil_03/revista/Rev_30/

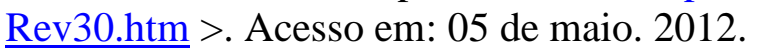

OLIVEIRA, Inocêncio. Prefácio. In: LINHARES, José (Org.). Responsabilidade na gestão pública: os desafios dos municípios. Brasília: Câmara dos Deputados, Edições Câmara, 2008. Disponível em: <http://bd.Camara.gov.br>. Acesso em: 15 de ago. 2011.

OLIVEIRA, Mariane de. TCE emite 164 "alertas" a municípios do Estado, inclusive à Cáceres. Jornal Oeste, Cáceres, dez. 2009. Disponível em: <http://www.jornaloeste.com.br/ index.php?pg=noticia\&idn=5330>. Acesso em: 26 de mar. 2012.

PEREIRA, J. R. T.; SILVA, A. V. Efeitos da Lei de Responsabilidade Fiscal sobre a prestação de contas em prefeituras baianas. In: $9^{\circ}$ Congresso da USP, 9., 2009, São Paulo. Anais... São Paulo: USP, 2009.

PISCITELLI, R. B.; ROSA, M. B.; TIMBÓ, M. Z. F. Contabilidade pública: uma abordagem da administração financeira pública. 8 ed. São Paulo: Atlas, 2004.

RAUSCH, Rita Buzzi; SOARES, Maurélio. Controle social na administração pública: a importância da transparência das contas públicas para inibir a corrupção. REPeC - Revista de Educação e Pesquisa em Contabilidade, Brasília, v. 4, n. 3, p. 23-43, set./dez. 2010.

SAMPIERI, Roberto. H; COLLADO, Carlos F.; LUCIO, Pilar B. Metodologia de Pesquisa. 3 ed. São Paulo: McGraw-Hill, 2006.

SANTOLIN, R.; JAIME JR, F. G.; REIS, J. C. dos. Lei de Responsabilidade Fiscal e implicações na despesa de pessoal e de investimento nos municípios mineiros: um estudo com dados em painel dinâmico. Est. Econ., São Paulo, v. 39, n. 4, p. 895-923, out./dez. 2009.

SANTOS, F. A. L. dos. et al. O papel dos Tribunais de Contas dos Estados diante do controle dos gastos públicos: um estudo no Tribunal de Contas do Estado de Alagoas. In: VII SEGeT Simpósio de excelência em gestão e tecnologia, 2010, Resende. Anais... Maceió: UFA, 2010.

SANTOS, S. R. T. dos S.; MURARO M. A influência da LRF nos procedimentos de controle interno: uma análise nos municípios gaúchos do Corede Produção. In: $18^{\circ}$ Congresso Brasileiro de Contabilidade, 2008, Gramado. Anais... Rio de Janeiro: UERJ, 2008.

dos; ALVES, T. W. O impacto da Lei de Responsabilidade Fiscal no desempenho financeiro e na execução orçamentária dos municípios no RS. RAP - Revista de Administração Pública, Rio de Janeiro, v. 45, n. 1, p. 181-208, jan./fev. 2011.

SILVA, Daiane Rodrigues da; BONACIM, Carlos Alberto Grespan. A Influência da Lei de Responsabilidade Fiscal na gestão das contas públicas segundo a percepção de um contador. Sociedade, Contabilidade e Gestão, Rio de Janeiro, v. 5, n. 2, p. 148-168, jul/dez 2010.

SILVA, F. P. C.; RIBEIRO FILHO, J. F. Uma análise das ressalvas do TCE-PE nas prestações de contas em prefeituras municipais no Estado de Pernambuco. REPeC - Revista de Educação e Pesquisa em Contabilidade, Brasília, v. 2, n. 2, p. 38-53, mai./ago. 2008. 
SODRÉ, Carlos de Azevedo. Lei de Responsabilidade Fiscal: Condição insuficiente para o ajuste fiscal. RAE eletrônica - Revista de Administração de Empresas, São Paulo, v. 1, n. 2, p. 2-15, jul./dez. 2002.

SÖTHE, A.; SÖTHE, V.; GUBIANI, C. A. O impacto da LRF: uma análise do desempenho das contas públicas municipais do estado do RS. In: XIV Seme $A D$ - Seminários em Administração, 2011, São Paulo. Anais... São Paulo: FEA/USP, 2011.

SOUZA, A. A. de. et al. Evidenciação contábil nos municípios mineiros: atendimento ao artigo 48 da Lei de Responsabilidade Fiscal. In: $18^{\circ}$ Congresso Brasileiro de Contabilidade, 2008, Gramado. Anais... Rio de Janeiro: UERJ, 2008.

SOUZA, Antonio Emanuel Andrade de. Desafios em dez anos de Lei de Responsabilidade Fiscal. Revista Técnica dos Tribunais de Contas - RTTC, Belo Horizonte, ano 1, n. 0, p. 291-296, set. 2010.

SOUZA, Fábia J. Viana de. et al. Análise do encaminhamento das contas dos municípios brasileiros do ano de 2008. Enfoque: Reflexão Contábil, Paraná, v. 29, n.2, p. 53-63, mai./ago. 2010.

TAVARES, Alessandra Schettino. O federalismo cooperativo no Brasil: o perfil do Estado brasileiro segundo a Constituição Federal de 1988. Brasília, 2009. Disponível em: <http://bd. camara.gov.br>. Acesso em: 02 de out. 2011.

VALINO, Reinaldo. A LRF e os Tribunais de Contas. Revista Técnica dos Tribunais de Contas - RTTC, Belo Horizonte, ano 1, n. 0, p. 291-298, set. 2010. 